\title{
Ocular Response to Millimeter Wave Exposure Under Different Levels of Humidity
}

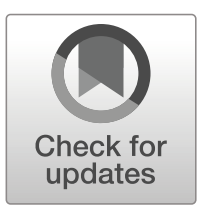

\author{
Masami Kojima ${ }^{1,2,3}$ (D) Cheng-Yu Tsai ${ }^{1,4,5} \cdot$ Yukihisa Suzuki $^{6} \cdot$ Kensuke Sasaki $^{7}$ • \\ Takafumi Tasaki $^{8,9} \cdot$ Masao Taki $^{6} \cdot$ Soichi Watanabe $^{7} \cdot$ Hiroshi Sasaki ${ }^{1,2}$
}

Received: 10 September 2018 / Accepted: 21 March 2019 / Published online: 30 March 2019

(C) The Author(s) 2019

\begin{abstract}
It is known that millimeter waves (MMW) are absorbed by surface tissue such as skin and the cornea. We previously demonstrated that MMW damages the eye by heat accumulation and transfer. To examine the influence of humidity on such damage, we investigated the difference in MMW-induced ocular tissue temperature increase under high $(70 \%)$ and low (30\%) relative humidity. Eyes of pigmented rabbits (Dutch, 11-15week old) were exposed unilaterally to $40-\mathrm{GHz} 200 \mathrm{~mW} / \mathrm{cm}^{2} \mathrm{MMW}$ for 5 or $30 \mathrm{~min}$ at the center of the pupillary area with a spot-focus type lens antenna. Infrared thermography was used to measure corneal surface temperature during exposure. Temperature of corneal stroma and lens nucleus were measured using a fluoroptic thermometer during 0 30-min exposure. To visualize the dynamic change of temperature and its distribution in the anterior chamber, saline containing $0.2 \%$ microencapsulated thermochromic liquid crystal (MTLC) was injected into the eye anterior chamber. All three temperature measurements were much higher under high than low humidity at $24{ }^{\circ} \mathrm{C}$ room temperature and MTLC results showed the same trend during MMW exposure. These findings indicate that humidity affects MMW-induced ocular temperature elevation. We showed that low humidity during MMW exposure decreased heat accumulation and transfer, whereas high humidity increased the thermal effect. The present data demonstrated that controlling the environmental humidity might have an impact on ocular damage in eyes exposed to MMW.
\end{abstract}

Keywords Millimeter wave $\cdot$ Rabbit eye $\cdot$ Humidity $\cdot$ Evaporation $\cdot$ Ocular temperature

Masami Kojima and Cheng-Yu Tsai contributed equally to this work.

Masami Kojima

m-kojima@kanazawa-med.ac.jp

Extended author information available on the last page of the article 


\section{Introduction}

Millimeter waves (MMW) comprise energy in the frequency range 30 to $300 \mathrm{GHz}$ of the electromagnetic spectrum. Over the past few decades, biological effects of MMW had only been investigated pertaining to their use in whole-body scanners at airports [1], radar systems (radio astronomy, police and military radar, vehicle collision prevention system) [2], and active denial systems (non-lethal weapons) [3]. Recently, MMW have been gaining more attention with their increasing use in broadband wireless communications.

Safety guidelines for MMW have been specified by the International Commission on Nonionizing Radiation Protection [4] and the International Committee on Electromagnetic Safety (ICES) of the Institute of Electrical and Electromagnetic Engineers [5].

Several studies have reported effects in the eyes by MMW exposure, but they mainly focused on surface tissue because of the shallow depth of penetration by radiation in this wavelength band [6,7]. Safety issues regarding tissue surface heating from MMW exposure have also been reviewed [8]. In addition, other recent studies have also reported acute effects from MMW exposure to the eye [9-12]. Nowadays, the number of people working under MMW exposure has been increasing, yet there is a paucity of data on the potential biological effects of such exposure.

Several studies of heat transfer in human eye have been published that inform evaluation of temperature distribution resulting from heat generation in eye tissues [13-15]. We previously reported that aqueous humor convection is an important factor in heat transfer from the cornea to the lens or vitreous humor [16]. Moreover, our previous study suggested that not only heat transfer within the cornea but heat exchange between the cornea surface and ambient air plays an important role in corneal damage from MMW exposure [12]. Therefore, the effect of ambient humidity, which may affect the rate of tear film evaporation, warrants investigation.

Eyeball surface moisture providing lubrication in blinking and smoothening of the corneal surface to enable a clear view are maintained by a thin layer of tear film [17]. Tear film is affected by ambient environmental conditions including humidity, temperature, and air flow [18, 19].

We investigated the effects of humidity on temperature elevation and transfer in eyes exposed to MMW and discussed the mechanisms underlying such ocular temperature elevation.

\section{Materials and Methods}

\subsection{Exposure System}

A standardized exposure system for in vivo rabbit eye was established at 40,75 , and $95 \mathrm{GHz}$ [12]. Note that the frequency $(40 \mathrm{GHz})$ was selected considering penetration depth into the eye. Briefly, the power source for 40-GHz continuous MMW comprised an 83650B signal generator (Agilent Technologies, Inc., Santa Clara, CA, USA) and a 40-W TWT amplifier (Ka Band, ETM Electromatic Inc., Newark, CA, USA). The MMW were transmitted through a conical horn antenna which had a $15-\mathrm{cm}$ diameter lens to spot-focus the power localizing it to the eye [12]. Power sensors monitored incident power to the antenna and reflected power from the antenna via a directional coupler to ensure the desired incident power density (Fig. 1a).

Rabbit eyes were exposed to MMW with an incident power density of $200 \mathrm{~mW} / \mathrm{cm}^{2}$ for 5 or $30 \mathrm{~min}$ at a distance of $135 \mathrm{~mm}$ from the lens antenna aperture to the corneal apex (Fig. 1b). 


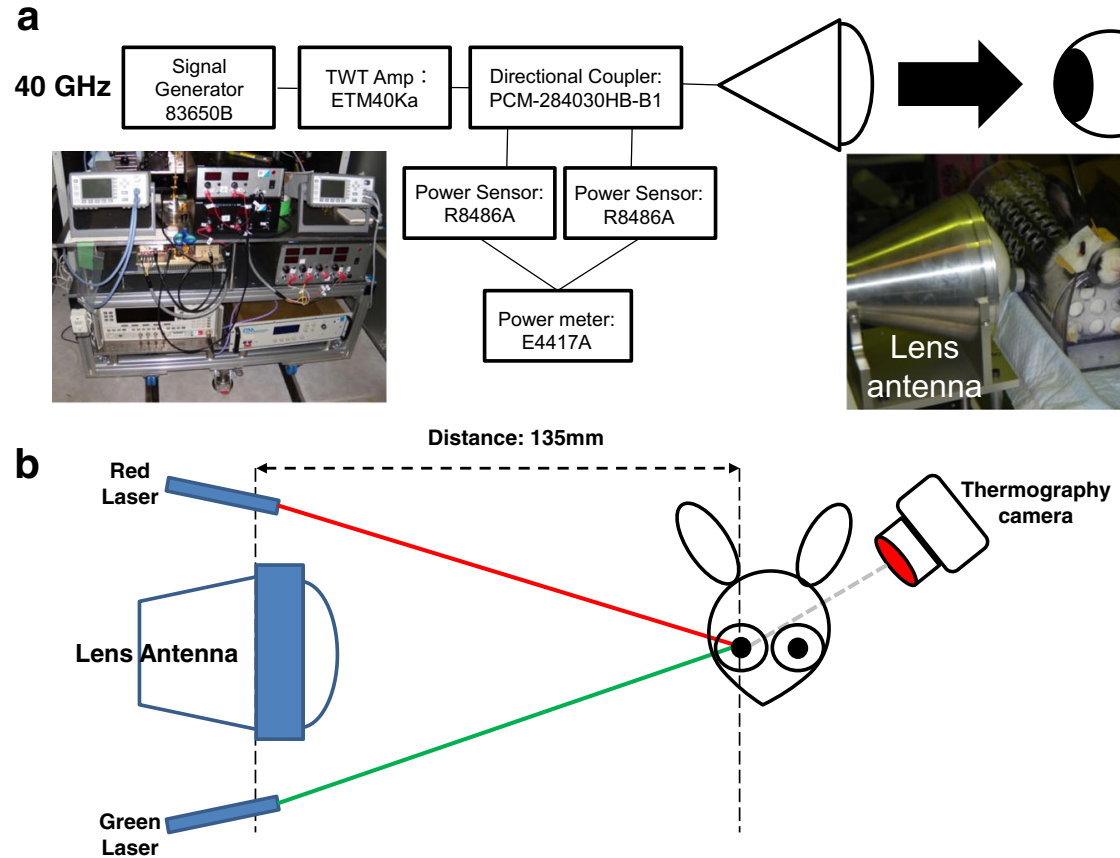

Fig. 1 Schematic of the MMW exposure system with an eye exposure positioning system

The incident power density was defined as the spatially averaged incident power density over an area of 13-mm diameter, which approximates the average size of the rabbit corneal region (Pigmented rabbit, Dutch-belted).

The center of the corneal surface was positioned in the line of maximum radiation from the antenna. The exposure point distance from the antenna surface to the corneal apex was determined by focusing red and green laser pointers on a target. After removal of the target, the apex of the rabbit's cornea was positioned at the exposure point according to the method of Kojima et al. [16] (Fig. 1b).

\subsection{Experimental Animals and Treatment}

All animal experiments were conducted in accordance with the Animal Study Guidelines of Kanazawa Medical University and the Association for Research in Vision and Ophthalmology Statement for the Use of Animals in Ophthalmic and Vision Research [20]. Specific pathogenfree pigmented rabbits ( $N=30$, Dutch-belted, 12-15-week old, all males, average weight 1.87 $\pm 0.06 \mathrm{~kg}$, range 1.75-1.99 kg, Sankyo Lab Service Co., Inc., Toyama, Japan) were exposed unilaterally to $200 \mathrm{~mW} / \mathrm{cm}^{2} \mathrm{MMW}$ for 5 or $30 \mathrm{~min}$ by lens antenna. Before exposure, eyes were examined by slit lamp microscopy (SL-130, Zeiss, Tokyo, Japan) to rule out presence of preexisting irregularities in the corneal surface and anterior segment. The pre-exposure examination included slit lamp images of the cornea, lens, and iris and fluorescent staining of corneal epithelium as described previously $[10,12,16]$. We exposed millimeter wave to one eye (right eye) and the other eye (left eye) was used as a non-exposed control.

Medetomidine hydrochloride $(0.8-1.0 \mathrm{mg} / \mathrm{kg}$, Domitor®, Orion Corporation, Espoo, Finland) was injected intramuscularly to induce systemic anesthesia during exposure and ocular 
examination. A 2\% lidocaine hydrochloride topical anesthetic (Xylocaine® 2\%, AstraZeneca, Osaka, Japan) was administered prior to insertion of the thermo probes or injection of the micro-encapsulated thermos-chromic liquid crystal (MTLC) (Japan Capsular Products, Tokyo) into the anterior chamber before exposure. The upper and lower eyelids were held open with tape to prevent blinking during exposure.

Saline drops, heated to $35-37^{\circ} \mathrm{C}$ to minimize any influence on MMW-induced temperature change, were administered to eyes as necessary to prevent corneal epithelial cell damage by corneal desiccation.

After the experiment, the rabbits were euthanized by pentobarbital sodium $(81 \mathrm{mg} / \mathrm{kg}$, Somnopentyl, Kyoritsu Seiyaku Corporation, Tokyo, Japan).

\subsection{Setup for Room Temperature, Relative Humidity}

Room temperature during MMW exposure was maintained at $24 \pm 2{ }^{\circ} \mathrm{C}$ by an air conditioner. Relative humidity was controlled to achieve $30 \%$ or $70 \%$ by a humidifier and a dehumidifier. In this experiment, from the viewpoint of animal welfare, only the relative humidity was changed while the room temperature was fixed at $24 \pm 2{ }^{\circ} \mathrm{C}$.

\subsection{Visualization of Anterior Chamber Convection}

MTLCs are 20-30- $\mu \mathrm{m}$ sized particles which change color with temperature [21-23]. MTLCs display a variety of colors spanning the visible spectrum for a fixed temperature bandwidth. Through 35 to $45^{\circ} \mathrm{C}$, they display red at the lower temperature, passing through yellow then green (above $39{ }^{\circ} \mathrm{C}$ ), then blue $\left(42{ }^{\circ} \mathrm{C}\right.$ ), and finally purple at the higher temperature. Saline containing $0.2 \%$ MTLC was injected into the anterior chamber of the rabbit eyes with a 30 gauge $(\mathrm{G})$ injection needle. A video camera was set at $90^{\circ}$ to the slit lamp illumination to record aqueous humor convection and change of MTLC color in the anterior chamber.

\subsection{Ocular Temperature Measurements}

Corneal stroma and lens nucleus temperatures during MMW exposure were recorded with a fluoroptic thermometer (Luxtron 790, Luxtron Corporation, Santa Clara, CA, USA), as described $[16,24]$. Briefly, the thermometer probes were inserted into the corneal stromal layer and lens nucleus, with the tip of each probe positioned at the center of the pupillary area after anesthesia. A slit-lamp microscope was used during insertion of the probes to ensure accurate positioning. Before starting to record, the topical anesthetic (heated to $35-37^{\circ} \mathrm{C}$ ) was instilled into the conjunctival sac, resulting in the corneal temperature dropping 1 or $2{ }^{\circ} \mathrm{C}$. Once the corneal temperature had stabilized, MMW exposure was started. The rabbit eyes were unilaterally and sequentially exposed to $200 \mathrm{~mW} / \mathrm{cm}^{2}$. An infrared camera (R300 Optional Lens, NEC Avio Infrared Technologies Co., Ltd., Tokyo, Japan) set above the rabbit eye recorded corneal surface temperature during exposure.

\subsection{Data Analysis}

Differences between outcomes of low (30\%) and high humidity (70\%) were analyzed using Student's paired $t$ test, taking $p<0.05$ as statistically significant. R version 3.5.1 [25] was used for the statistical analysis. Before performing Student's paired $t$ test, the assumption of normal 
distribution and equal variance of the data were tested by the Kolmogorov-Smirnov test and $F$ test, respectively. All sets of sample data was proven suitable for the parametric test.

\section{Results}

Figure 2 shows MTLC color change in the anterior chamber during 40-GHz $200 \mathrm{~mW} / \mathrm{cm}^{2}$ MMW exposure for 5 min under the two humidity conditions. After 30-s exposure, the upper part of the anterior chamber near the cornea side showed MTLC color change under high but not low humidity (Fig. 2a, e). Interesting results were obtained when exposure time reached $1 \mathrm{~min}$; there was no color change under the low humidity environment (Fig. 2b), but two-thirds of the anterior chamber showed a marked color change which indicated a temperature of 38$40{ }^{\circ} \mathrm{C}$ under high humidity (Fig. 2f). After 2-min exposure, MTLC showed green (around $40{ }^{\circ} \mathrm{C}$ ) in the upper part of the anterior chamber under low humidity (Fig. 2c). In contrast, the whole of the anterior chamber showed blue and green, indicating higher temperature (over $40{ }^{\circ} \mathrm{C}$ ) under high humidity after 2-min exposure (Fig. 2g). At 4-min exposure, the temperature of the anterior chamber was increased under both humidity environments (Fig. 2d, h), especially under high humidity, which showed over $40{ }^{\circ} \mathrm{C}$ (blue color tone) in the whole anterior chamber (Fig. 2h).

Temperatures of the corneal surface, corneal stroma, and lens during $200 \mathrm{~mW} / \mathrm{cm}^{2} 30-\mathrm{min}$ exposure were all higher under the high (70\%) than the low (30\%) humidity environment

\section{$40 \mathrm{GHz} 200 \mathrm{~mW} / \mathrm{cm}^{2} 5 \mathrm{~min}$ Exposure}

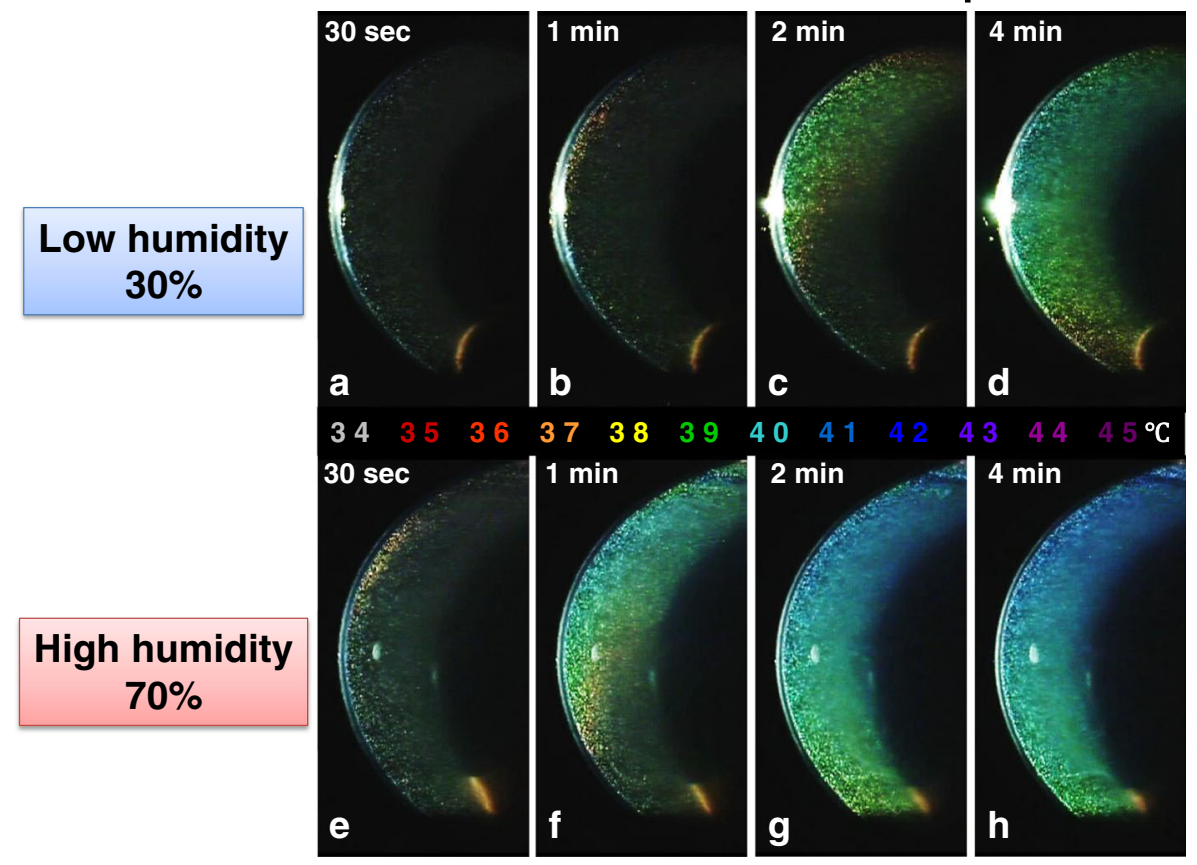

Fig. 2 Temperatures of anterior chamber measured by MTLC during MMW exposure $40 \mathrm{GHz} 200 \mathrm{~mW} / \mathrm{cm}^{2}: \mathbf{a}, \mathbf{e}$ $30 \mathrm{~s}$ after exposure onset, b, f $1 \mathrm{~min}$ after exposure onset, c, g $2 \mathrm{~min}$ after exposure onset, d, h $4 \mathrm{~min}$ after exposure onset 
(Figs. 3, 4, and 5). Soon after exposure onset, there was a steep temperature elevation at all three measurement sites. Under low humidity, the corneal surface temperature detected by thermography reached $35.5{ }^{\circ} \mathrm{C}$ whereas that under high humidity reached $37.3{ }^{\circ} \mathrm{C}$ (Fig. 3). Under low humidity, the corneal stroma temperature detected by fluoroptic thermometer reached $36.6{ }^{\circ} \mathrm{C}$ whereas that under high humidity reached $38.3^{\circ} \mathrm{C}$ (Fig. 4), similarly those for the lens nucleus were $35.6{ }^{\circ} \mathrm{C}$ and $37.3{ }^{\circ} \mathrm{C}$, respectively (Fig. 5), with the averaged three sites showing a significant difference in $\mathrm{MMW}$-induced temperature elevation by humidity level ( $p<0.05$, Fig. 6).

\section{Discussion}

Thermal ocular effects from exposure to 35 and 107-GHz MMW have been reported [6]. Karampatzakis et al. demonstrated by a computational approach using a 3D numerical model that aqueous humor flow in the anterior chamber plays an important role in heat transfer [14]. Another study showed thermal effects caused by MMW exposure not only in the cornea but in the lens [10]. These reports suggested that the major effect of MMW exposure is heat accumulation, especially in the cornea. ICNIRP guidelines for high-frequency electromagnetic energy such as MMW indicate that the surface of the eye absorbs most of the energy of MMW irradiation [4], so we believe that energy absorption by the cornea is a very important issue.

Our previous study indicated that we should assess thermal transfer in the eyeball with regard to the tear film layer on the cornea outer surface and aqueous humor convection within the anterior chamber $[12,16]$. The cornea surface is covered by a thin tear film, which protects it from direct exposure to air. Tear film is the outermost surface element of the ocular system

\section{$40 \mathrm{GHz} 200 \mathrm{~mW} / \mathrm{cm}^{2} 30$ min Exposure Corneal Surface Temperature}

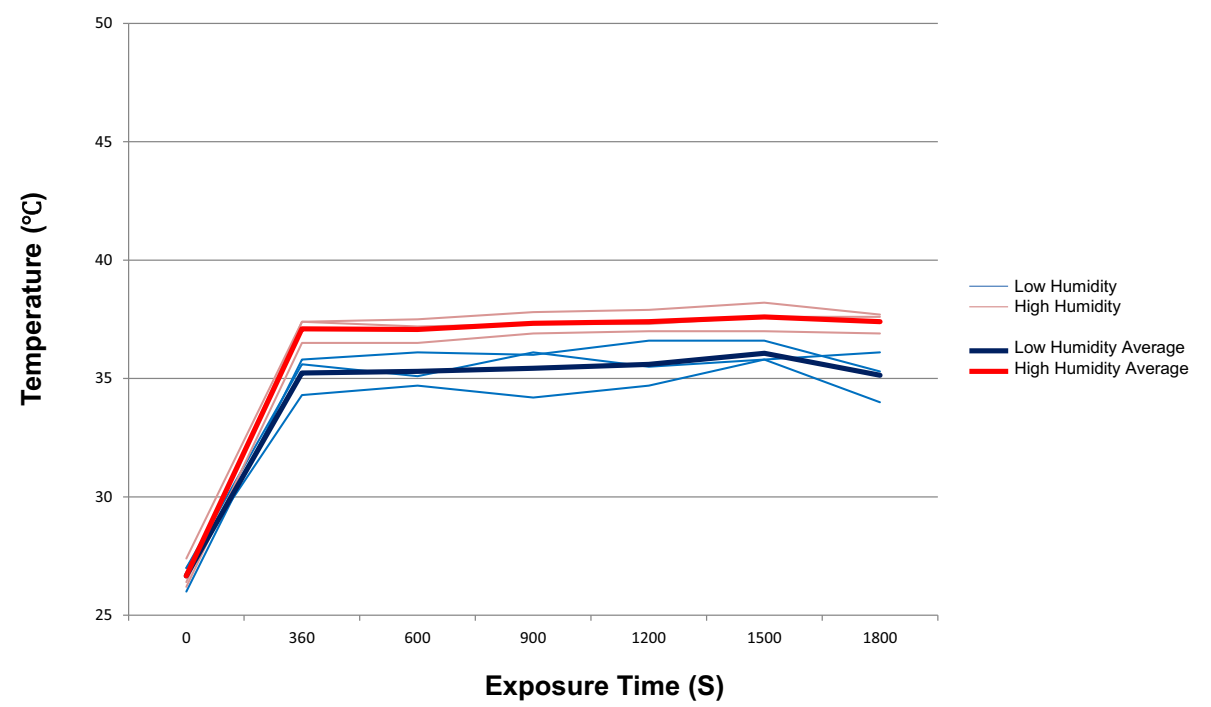

Fig. 3 Corneal surface temperature change induced by 40-GHz $200 \mathrm{~mW} / \mathrm{cm}^{2}$ 30-min exposure 


\section{$40 \mathrm{GHz} 200 \mathrm{~mW} / \mathrm{cm}^{2} 30 \mathrm{~min}$ Exposure Corneal Stroma Temperature}

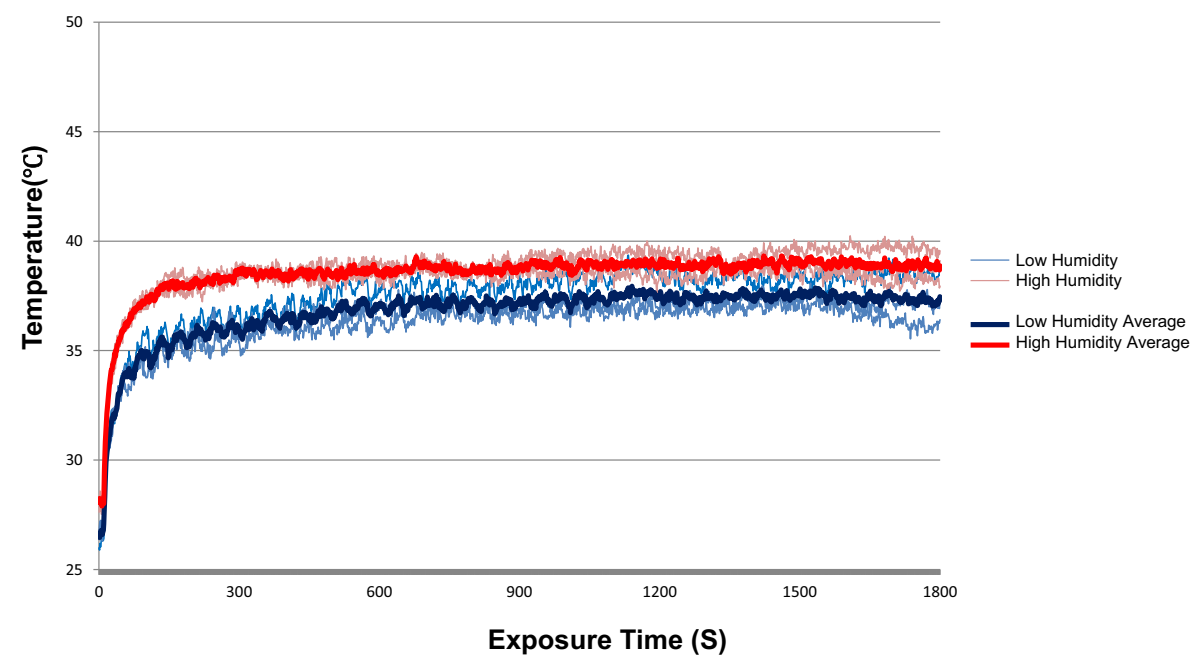

Fig. 4 Corneal stroma temperature elevation during exposure to $200 \mathrm{~mW} / \mathrm{cm}^{2}$ at $40 \mathrm{GHz}$ for $30 \mathrm{~min}$

between the cornea and the outside environment. It plays an important role in optical function. Evaporation of aqueous tears has been studied as a major factor in tear film dynamics and may impact ocular temperature [17]. Evaporation of tears is affected by temperature, air velocity,

\section{$40 \mathrm{GHz} 200 \mathrm{~mW} / \mathrm{cm}^{2} 30 \mathrm{~min}$ Exposure Lens Temperature}

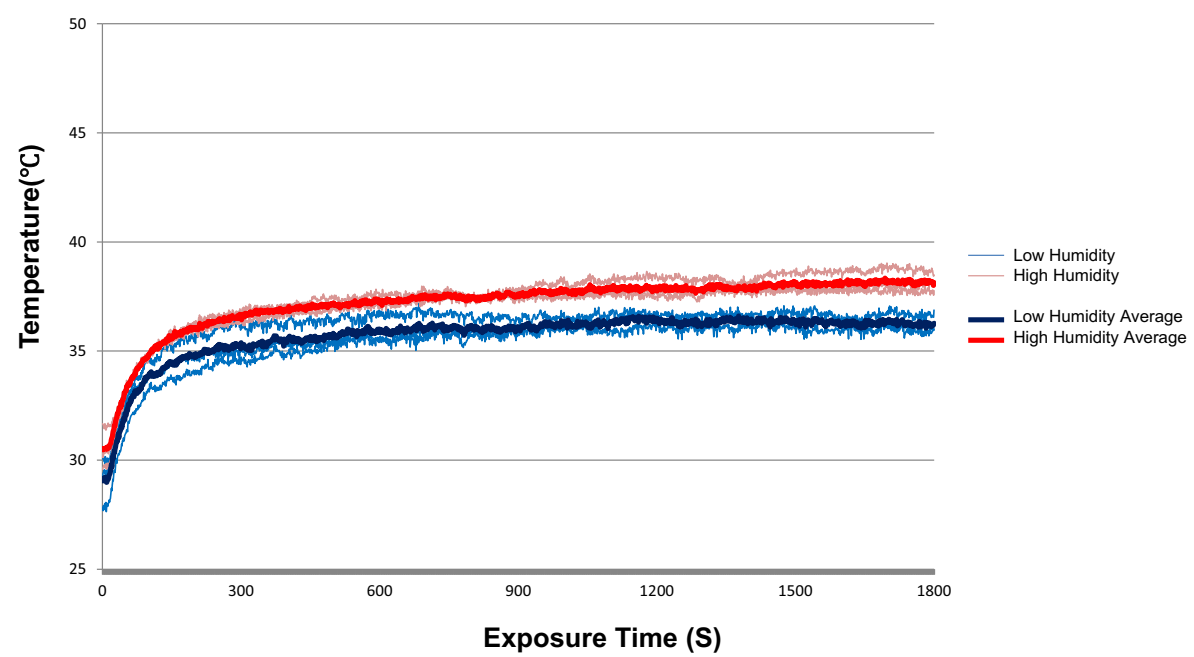

Fig. 5 Lens temperature elevation during exposure to $200 \mathrm{~mW} / \mathrm{cm}^{2}$ at $40 \mathrm{GHz}$ for $30 \mathrm{~min}$ 

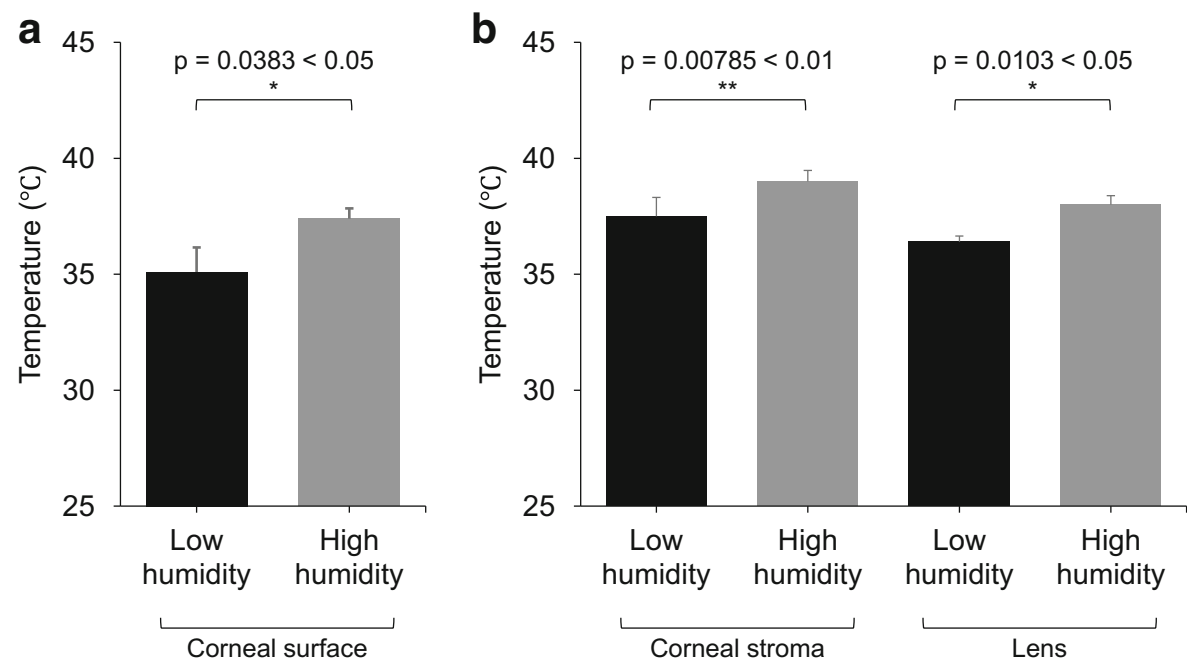

Fig. 6 Relationship between temperature change (a corneal surface, b corneal stroma, lens) during $40 \mathrm{GHz}$ $200 \mathrm{~mW} / \mathrm{cm}^{2}$ and humidity $(30 \%, 70 \%)$. a Corneal surface temperature was detected by thermography. b Temperatures of corneal stroma and lens were measured by fluoroptic thermometer

and relative humidity [26]. The volume of evaporated tear loss ranges from 40 to $60 \%$ and is dependent on environmental conditions including relative humidity [27]. Environmental factors have long been known to influence the tear film. Under environmental stress, such as low relative humidity or high air velocity, faster evaporation rates and thinning of the tear film predispose the cornea to dry spot formation, which may lead to dry eye symptoms and changes in the corneal epithelium [27-30].

The purpose of the present study was to determine the relationship between relative humidity and ocular temperature change over a period of 5- or 30-min exposure to MMW. We investigated ocular temperature change to elucidate potential risks of ocular damage due to different evaporation rates under different relative humidity environments. In this study, statistically significant increases in temperature occurred at the corneal surface, corneal stroma, and lens nucleus by exposure to MMW under a high humidity environment. It has been reported that transpiration rate from the corneal surface decreases by 20-25\% when $30 \%$ humidity increases to $40 \%$ [31]. Abusharha and Pearce reported that tear film evaporation rate significantly increased with exposure to a dry environment [32]. From these findings, we can deduce that humid environments have an important impact on tear film evaporation rate. Since heat accumulated on the surface of the eye during MMW exposure, we suggest that a low evaporation rate might increase the thermal effect during MMW exposure. This temperature change under a high humidity $(70 \%)$ environment could explain the evaporation effect during MMW exposure.

Ocular symptoms including itch, burning sensation, and dry eye are commonly reported by individuals working in closed and dry environmental conditions, which are characterized by low humidity [33, 34]. Although low humidity might cause ocular surface symptoms, our data indicated that with the increase in tear evaporation, corneal surface temperature decreased because of dissipation of the heat. It is clear from this study that controlling the humidity, with for example a humidifier, may decrease the tear film heat evaporation within MMW exposure guidelines. 
The present study demonstrated a significant difference in MMW-induced temperature change by humidity environment. The exact mechanisms of this outcome remain unclear. It is likely that an increase in humidity results in a decrease in tear film evaporation, such that some heat induced by MMW exposure accumulates in the eye. Conversely, reduction in humidity is likely to cause an increase in tear evaporation, such that some heat induced by MMW exposure is lost to tear film evaporation.

Let us consider the contribution of relative humidity to temperature elevation at the corneal surface during exposure to over $40 \mathrm{GHz}$ MMW. We expect that the contribution will increase with decreasing depth of penetration of MMW into the eye. While MMW penetrate the anterior chamber at $40 \mathrm{GHz}$, the penetration depth decreases with increasing frequency [35, 36]. Thus, the variation in temperature elevation by relative humidity is expected to increase at frequencies above $40 \mathrm{GHz}$.

We demonstrated that humidity affects ocular temperature elevation that is induced by MMW exposure. Going forwards, we should consider environmental factors, especially relative humidity, during MMW exposure.

\section{Conclusion}

The effect of relative humidity on ocular temperature rise during MMW exposure was investigated. It was shown that ocular temperature was significantly elevated under high than low humidity. MTLC data indicated that there is greater heat transfer to intraocular regions under MMW exposure in a high (70\%) than low (30\%) humidity environment. It was demonstrated that environment humidity is an important factor in heat transfer in eyes exposed to MMW. Controlling humidity may have a great impact on ocular effects of MMW exposure.

Acknowledgements This work was supported by Ministry of Internal Affairs and Communications, Japan. The authors declare that they have no conflict of interest. The authors are indebted to Dr. Taiji Sakai, Ms. Yoko Yamashiro, Dr. Nailia Hasanova, and Ms. Mari Seto for their technical assistance, and to Mr. David Price for English proofreading.

Open Access This article is distributed under the terms of the Creative Commons Attribution 4.0 International License (http://creativecommons.org/licenses/by/4.0/), which permits unrestricted use, distribution, and reproduction in any medium, provided you give appropriate credit to the original author(s) and the source, provide a link to the Creative Commons license, and indicate if changes were made.

\section{References}

1. J. E. Moulder, "Risks of exposure to ionizing and millimeter-wave radiation from airport whole-body scanners," Radiat Res, vol. 177, pp. 723-726, 2012.

2. D. Rotkovská, J. Moc, J. Kautská, A. Bartonicková, J. Keprtová, and M. Hofer, "Evaluation of the biological effects of police radar RAMER 7F," Environ Health Perspect, vol. 101, pp. 134-136, 1993.

3. J. C. Debouzy, D. Crouzier, V. Dabouis, R. Malabiau, C. Bachelet, and A. Perrin, "Biologic effects of millimeteric waves $(94 \mathrm{GHz})$. Are there long term consequences?," Pathol Biol (Paris), vol. 55, pp. 246255, 2007. [French]

4. International Commission on Non-Ionizing Radiation Protection, "Guidelines for limiting exposure to timevarying electric, magnetic, and electromagnetic fields (up to $300 \mathrm{GHz}$ )”, Health Phys, vol. 74, pp. 494-522, 1998. 
5. IEEE International Committee on Electromagnetic Safety, "IEEE standard for safety levels with respect to human exposure to radio frequency electromagnetic fields, $3 \mathrm{kHz}$ to $300 \mathrm{GHz}$ ", IEEE Std C95.1-2005 (Revision of IEEE Std C95.1-1991), pp. 1-238, 2006.

6. S. W. Rosenthal, L. Birenbaum, I. T. Kaplan, W. Metlay, W. Z. Snyder, and M. M. Zaret, "Effects of 35 and $107 \mathrm{GHz}$ CW microwaves on the rabbit eye". In Biological Effects of Electromagnetic Waves, ed. By C. C. Johnson and M. L. Shore (HEW Publication (FDA) 77-8010, Rockville, 1976), pp. 110-128.

7. H. A. Kues, S. A. D'Anna, R. Osiander, W. R. Green, and J. C. Monahan, "Absence of ocular effects after either single or repeated exposure to $10 \mathrm{~mW} / \mathrm{cm}^{2}$ from a $60 \mathrm{GHz} \mathrm{CW}$ source," Bioelectromagnetics, vol. 20, pp. 463-473, 1999.

8. K. L. Ryan, J. A. D'Andrea, J. R. Jauchem, and P. A. Mason, "Radio frequency radiation of millimeter wave length: potential occupational safety issues relating to surface heating," Health Phys, vol. 78, pp. 170-181, 2000 .

9. S. Chalfin, J. A. D'Andrea, P. D. Comeau, M. E. Belt, and D. J. Hatcher, "Millimeter wave absorption in the nonhuman primate eye at $35 \mathrm{GHz}$ and $94 \mathrm{GHz}$," Health Phys, vol. 83, pp. 83-90, 2002.

10. M. Kojima, M. Hanazawa, Y. Yamashiro, H. Sasaki, S. Watanabe, M. Taki, Y. Suzuki, A. Hirata, Y. Kamimura, and K. Sasaki, "Acute ocular injuries caused by $60-$ Ghz millimeter-wave exposure," Health Phys, vol. 97, pp. 212-218, 2009.

11. K. R. Foster, J. A. D'Andrea, S. Chalfin, and D. J. Hatcher, "Thermal modeling of millimeter wave damage to the primate cornea at $35 \mathrm{GHz}$ and $94 \mathrm{GHz}, "$ Health Phys, vol. 84, pp. 764-769, 2003.

12. M. Kojima, Y. Suzuki, K. Sasaki, M. Taki, K. Wake, S. Watanabe, M. Mizuno, T. Tasaki, and H. Sasaki, "Ocular Effects of Exposure to 40, 75, and 95 GHz Millimeter Waves," J Infrared Milli Terahz Waves, vol. 39, pp. 912-925, 2018.

13. E. Y. Ng and E. H. Ooi, "Ocular surface temperature: a 3D FEM prediction using bioheat equation," Comput Biol Med, vol. 37, pp. 829-835, 2007.

14. A. Karampatzakis and T. Samaras, "Numerical model of heat transfer in the human eye with consideration of fluid dynamics of the aqueous humour," Phys Med Biol, vol. 55, pp. 5653-5665, 2010.

15. E. H. Ooi and E. Y. K. Ng, "Effects of natural convection within the anterior chamber on the ocular heat transfer," Int J Numer Meth Biomed Engng, vol. 27, pp. 408-423, 2011.

16. M. Kojima, Y. Suzuki, C.-Y. Tsai, K. Sasaki, K. Wake, S. Watanabe, M. Taki, Y. Kamimura, A. Hirata, K. Sasaki, and H. Sasaki, "Characteristics of ocular temperature elevations after exposure to quasi- and millimeter waves (18-40 GHz)," J Infrared Milli Terahz Waves, vol. 36, pp. 390-399, 2015.

17. T. J. Dursch, W. Li, B. Taraz, M. C. Lin, and C. J. Radke, "Tear-Film Evaporation Rate from Simultaneous Ocular-Surface Temperature and Tear-Breakup Area," Optom Vis Sci, vol. 95, pp. 5-12, 2018.

18. D. Borchman, G. N. Foulks, M. C. Yappert, J. Mathews, K. Leake, and J. Bell, "Factors affecting evaporation rates of tear film components measured in vitro," Eye Contact Lens, vol. 35, pp. 32-37, 2009.

19. K. Hisatake, S. Tanaka, Y. Aizawa, J. W. Hinchley, and G. W. Himus, "Evaporation rate of water in a vessel, " J Appl Phys, vol. 73, pp. 7395-7401, 1993.

20. ARVO Statement for the Use of Animals in Ophthalmic and Vision Research https://www.arvo. org/About/policies/statement-for-the-use-of-animals-in-ophthalmic-and-vision-research/. Accessed 7 June 2018.

21. J. L. Fergason, "Liquid crystals in nondestructive testing," Appl Opt, vol. 7, pp. 1729-1737, 1968.

22. D. Dabiri and M. Gharib, "Digital particle image thermometry: The method and implementation," Exp Fluids, vol. 11, pp. 77-86, 1991.

23. Y. Suzuki, M. Baba, M. Taki, K. Fukunaga, and S. Watanabe, "Imaging the 3D temperature distributions caused by exposure of dielectric phantoms to high-frequency electromagnetic fields," IEEE Transactions on Dielectrics and Electrical Insulation, vol. 13, pp. 744-750, 2006.

24. M. Kojima, I. Hata, K. Wake, S. Watanabe, Y. Yamanaka, Y. Kamimura, M. Taki, and K. Sasaki, "Influence of anesthesia on ocular effects and temperature in rabbit eyes exposed to microwaves," Bioelectromagnetics, vol. 25, pp. 228-233, 2004.

25. R Core Team, "R: A Language and Environment for Statistical Computing," R Foundation for Statistical Computing, Vienna, 2018. https://www.R-project.org. Accessed 20 December 2018.

26. J. C. Wojtowicz and J. P. McCulley, "Assessment and impact of the time of day on aqueous tear evaporation in normal subjects," Eye Contact Lens, vol. 35, pp. 117-119, 2009.

27. J. P. McCulley, E. Uchiyama, J. D. Aronowicz, and I. A. Butovich, "Impact of evaporation on aqueous tear loss," Trans Am Ophthalmol Soc, vol. 104, pp. 121-128, 2006.

28. P. Wolkoff, J. K. Nojgaard, P. Troiano and B. Piccoli, "Eye complaints in the office environment: precorneal tear film integrity influenced by eye blinking efficiency," Occup Environ Med, vol. 62, pp. 4-12, 2005.

29. N. M. Wyon and D. P. Wyon, "Measurement of acute response to draught in the eye," Acta Ophthalmol (Copenh), vol. 65, pp. 385-392, 1987. 
30. E. Uchiyama, J. D. Aronowicz, I. A. Butovich, and J. P. McCulley, "Increased evaporative rates in laboratory testing conditions simulating airplane cabin relative humidity: an important factor for dry eye syndrome," Eye Contact Lens, vol. 33, pp. 174-176, 2007.

31. W. D. Mathers, "Ocular evaporation in meibomian gland dysfunction and dry eye," Ophthalmology, vol. 100, pp. 347-351, 1993.

32. A. A. Abusharha and E. I. Pearce, "The effect of low humidity on the human tear film," Cornea, vol. 32, pp. 429-434, 2013.

33. P. Wolkoff, ""Healthy" eye in office-like environments," Environ Int, vol. 34, pp. 1204-1214, 2008.

34. J. L. Rios, J. L. Boechat, A. Gioda, C. Y. dos Santos, F. R. de Aquino Neto, and J. R. Lapa e Silva, "Symptoms prevalence among office workers of a sealed versus a non-sealed building: associations to indoor air quality," Environ Int, vol. 35, pp. 1136-1141, 2009.

35. K. Sasaki, T. Sakai, T. Nagaoka, K. Wake, S. Watanabe, M. Kojima, N. Hasanova, H. Sasaki, K. Sasaki, Y. Suzuki, M. Taki, Y. Kamimura, A. Hirata, and H. Shirai, "Dosimetry Using a Localized Exposure System in the Millimeter-Wave Band for in vivo Studies on Ocular Effects," IEEE Transactions on Microwave Theory and Techniques, vol. 62, pp. 1554-1564, 2014.

36. K. Sasaki, Y. Isimura, K. Fujii, K. Wake, S. Watanabe, M. Kojima, R. Suga, and O. Hashimoto, "Dielectric property measurement of ocular tissues up to $110 \mathrm{GHz}$ using $1 \mathrm{~mm}$ coaxial sensor," Phys Med Biol, vol. 60, pp. $6273-6288,2015$.

Publisher's Note Springer Nature remains neutral with regard to jurisdictional claims in published maps and institutional affiliations.

\section{Affiliations}

\section{Masami Kojima ${ }^{1,2,3} \cdot$ Cheng-Yu Tsai $^{1,4,5} \cdot$ Yukihisa Suzuki $^{6} \cdot$ Kensuke Sasaki $^{7} \cdot$ Takafumi $^{-}$ Tasaki $^{8,9} \cdot{\text { Masao } \text { Taki }^{6} \cdot \text { Soichi Watanabe }}^{7} \cdot$ Hiroshi Sasaki ${ }^{1,2}$}

1 Division of Vision Research for Environmental Health, Medical Research Institute, Kanazawa Medical University, Kahoku, Japan

2 Department of Ophthalmology, Kanazawa Medical University, Kahoku, Japan

3 School of Nursing, Kanazawa Medical University, 1-1 Daigaku, Uchinada, Kahoku, Ishikawa 920-0293, Japan

4 Department of Optometry, University of Kang Ning, Taipei, Taiwan

5 Department of Veterinary Medicine, National Chung-Hsing University, Taichung, Taiwan

6 Department of Electrical Engineering, Graduate School of Engineering, Tokyo Metropolitan University, Tokyo, Japan

7 National Institute of Information and Communications Technology, Tokyo, Japan

8 Division of Protein Regulation Research, Medical Research Institute, Kanazawa Medical University, Kahoku, Japan

9 Department of Medical Zoology, Kanazawa Medical University, Kahoku, Japan 